\title{
Circadian rhythm of salivary cortisol, plasma cortisol, and plasma ACTH in end-stage renal disease
}

\author{
Hershel Raff ${ }^{1,2,3,5}$ and Hariprasad Trivedi ${ }^{4}$ \\ ${ }^{1}$ Division of Endocrinology, Department of Medicine ${ }^{2}$ Department of Surgery ${ }^{3}$ Department of Physiology \\ ${ }^{4}$ Division of Nephrology, Department of Medicine, Medical College of Wisconsin, Milwaukee, Wisconsin 53226, USA \\ ${ }^{5}$ Endocrine Research Laboratory, Aurora St Luke's Medical Center, 2801 W Kinnickinnic Parkway, Suite 245, \\ Milwaukee, Wisconsin 53215, USA
}

\begin{abstract}
Objective: Patients with end-stage renal disease (ESRD) can display the features of endogenous hypercortisolism but are difficult to evaluate for Cushing's syndrome. We evaluated the circadian rhythm of plasma compared with salivary cortisol in subjects with ESRD.

Design: Plasma and salivary cortisol and plasma ACTH samples were drawn frequently over $24 \mathrm{~h}$ in an inpatient research unit in stable ESRD subjects on daytime chronic hemodialysis $(n=16)$ vs controls $(n=8)$.

Methods: Plasma cortisol was measured every $2 \mathrm{~h}$ from 0800 to $0600 \mathrm{~h}$ the following day. Salivary cortisol was measured every $2 \mathrm{~h}$, except between 2400 and $0400 \mathrm{~h}$ (sleep time). Plasma ACTH measured in a subset of samples and C-reactive protein (CRP) was measured as a marker of a subclinical inflammatory state in all subjects.

Results: ESRD subjects had a discernable circadian rhythm in plasma and salivary cortisol, but with a significantly higher nadir (1800-2400 h) compared with the controls $(P=0.016-<0.001)$. After excluding four ESRD subjects without a normal circadian rhythm, the ESRD subjects still had higher nadir plasma and salivary cortisol and plasma ACTH compared with controls. There was no difference in the correlation of salivary and plasma cortisol in control vs ESRD subjects. ESRD subjects had higher CRP levels compared with controls.

Conclusions: ESRD subjects had increased late-night plasma and salivary cortisol and plasma ACTH levels. Late-night salivary cortisol is a reliable index of plasma cortisol in ESRD patients.
\end{abstract}

\author{
Correspondence \\ should be addressed to $\mathrm{H}$ Raff \\ at Endocrine Research \\ Laboratory, Aurora St Luke's \\ Medical Center \\ Email \\ hraff@mcw.edu
}

Endocrine Connections (2013) 2, 23-31

\section{Introduction}

The measurement of salivary cortisol has emerged as a first-line test in the evaluation of the hypothalamicpituitary-adrenal (HPA) axis in humans and, in particular, for the diagnosis of endogenous hypercortisolism

http://www.endocrineconnections.org

DOI: 10.1530/EC-12-0058
(Cushing's syndrome) $(1,2,3,4,5,6,7)$. It is now accepted that an increased late-night salivary cortisol (at the circadian nadir) has $90-95 \%$ sensitivity and specificity for the diagnosis of Cushing's syndrome $(6,7)$.

(C) 2012 The Authors. Published by BioScientifica Ltd. This is an Open Access article distributed under the terms of the Creative Commons Attribution License, which permits unrestricted use, distribution, and reproduction in any medium, provided the original author and source are credited. 
In patients with normal renal function, salivary cortisol concentration is highly correlated with plasma free cortisol (7). However, its value in the assessment of possible endogenous hypercortisolism in patients with end-stage renal disease (ESRD) is not known. Other tests of HPA axis function are problematic in patients with diminished renal function. The inability to assess 24-h urine free cortisol in an anuric patient is self-evident. Furthermore, assessment of serum cortisol after dexamethasone suppression is also difficult to validate as plasma binding protein concentrations and dexamethasone clearance can be significantly altered with decreased renal function $(8,9,10)$. Our reference laboratory often receives inquiries as to whether late-night salivary cortisol can be used to evaluate the possibility of endogenous Cushing's syndrome in patients with chronic kidney failure and we have been unable to provide a definitive answer based on previous studies $(1,2)$.

In patients with ESRD on chronic dialysis therapy, the mortality rate has remained close to $20 \%$ per year, about half due to cardiovascular diseases $(11,12,13)$. In addition, uremic morbidities are extensive and include hypertension, metabolic bone disease, anemia, immunosuppression, and neuromuscular, dermatological, and endocrine disturbances $(12,13)$. Although the causes of morbidity and mortality are multifactorial, the types of morbidities suggest that increased cortisol secretion could play a contributory role. In fact, it has been observed that there are significant similarities between the morbidity of Cushing's syndrome and renal failure $(8,9)$. Thus, it is important to be able to properly assess the HPA axis in ESRD subjects.

The current study was designed to evaluate the circadian rhythm of the HPA axis using an intensive blood sampling protocol over $22 \mathrm{~h}$ in subjects with ESRD compared with a group of control subjects with normal renal function. Simultaneous salivary and plasma cortisol samples were taken when the subjects were awake to determine the value of salivary cortisol in the assessment of HPA axis in patients with ESRD.

\section{Materials and methods}

\section{Subjects}

The study was approved by the Medical College of Wisconsin Institutional Review Board and informed written consent was obtained from all subjects. Subjects were recruited from patients during usual clinical care or by referral from colleagues. Controls were recruited by

http://www.endocrineconnections.org

DOI: 10.1530/EC-12-0058 referral from colleagues, volunteering employees, and from volunteers who heard about the study by word of mouth. The study population consisted of adult (age 18 years and older) subjects on chronic maintenance hemodialysis therapy for at least 30 days $(n=16)$ and control subjects $(n=8)$ without a history of kidney disease with an estimated glomerular filtration rate $>70 \mathrm{ml} / \mathrm{min}$ per $1.73 \mathrm{~m}^{2}$. The primary outcome of the study was the comparison of the circadian rhythm of plasma and salivary cortisol. Exclusions included diabetes mellitus, subjects on oral corticosteroid preparations, pregnant women (serum pregnancy testing performed in women of child-bearing age), or unwillingness to participate and adhere to the protocol requirements. Subjects were not known to use inhaled steroids. Topical ointments and creams were not used during the sampling protocol. For 5 days before admission to the adult Translational Research Unit (TRU), subjects consumed a research diet tailored to contain $1000 \mathrm{mg}$ phosphorus and $1200 \mathrm{mg}$ calcium per day. In all other respects, the diet was similar to their usual diet.

\section{Study day}

Subjects were admitted to the adult TRU the evening before the study day. ESRD subjects were sampled on a non-dialysis day; this was usually the day after their normal dialysis day. In the morning ( $\sim 0700 \mathrm{~h})$ after TRU admission, an intravenous catheter was placed. Blood was sampled for plasma cortisol every $2 \mathrm{~h}$ from 0800 to $0600 \mathrm{~h}$ the following morning. Additional testing for plasma ACTH was done from blood drawn at 0800, 1200, 1800, 2200, 2400, and 0600 h. Salivary samples for cortisol were obtained using the Salivette (Sarstedt, Nümbrecht, Germany) every $2 \mathrm{~h}$ except for the $2400-0400 \mathrm{~h}$ samples while the subjects were sleeping. Breakfast was provided at $\sim 0800 \mathrm{~h}$, lunch was provided at $\sim 1200 \mathrm{~h}$ (after the blood draw), dinner was provided at $\sim 1700 \mathrm{~h}$, and a late evening snack was provided at $\sim 2000 \mathrm{~h}$. A sleep pattern history was noted by the TRU nursing staff.

\section{Study day hormone measurements}

Salivary cortisol and plasma ACTH were measured by validated immunoassays described in detail previously $(14,15)$. Plasma cortisol was measured using a Corti-cote assay (MP Biomedical, Solon, OH, USA). The sensitivity of this assay is $1.9 \mathrm{nmol} / \mathrm{l}$, intra-assay precision $4.7-7.9 \%$, and interassay precision $6.6-7.6 \%$. Cross-reactivity was cortisol $100 \%$, prednisolone $94.1 \%$, prednisone $1.2 \%$,

(c) 2012 The Authors. Published by BioScientifica Ltd. This is an Open Access article distributed under the terms of the Creative Commons Attribution License, which permits unrestricted use, distribution, and reproduction in any medium, provided the original author and source are credited. 
11-deoxycortisol $2.2 \%$, prednisone $1.2 \%$, and corticosterone $1.2 \%$; all other cross-reactivities were $<1.0 \%$. Plasma human C-reactive protein (CRP) was measured by enzyme immunoassay (Quantikine, R\&D Systems, Minneapolis, $\mathrm{MN}$, USA). The minimum detectable concentration is $0.1 \mathrm{nmol} / \mathrm{l}$, intra-assay precision $3.8-8.3 \%$, and interassay precision $6.0-7.0 \%$. There are no known significant cross-reactants. The reference range is reported to be $1.0-40.0 \mathrm{nmol} / 1$.

\section{Calculations and statistical analysis}

Criteria for a normal circadian rhythm were based on previous studies $(7,14,16)$ as follows: plasma cortisol at $2400 \mathrm{~h}<210 \mathrm{nmol} / \mathrm{l}$, salivary cortisol at $2200 \mathrm{~h}<$ $6.0 \mathrm{nmol} / \mathrm{l}$, ratio of 0800:2200 h plasma, and/or salivary cortisol $>2$. To be as conservative as possible and since salivary cortisol results were considered the dependent variable in the comparison of salivary and plasma cortisol, the upper cutoff for late-night salivary cortisol was set at the $99 \%$ confidence limit rather than $97.5 \%$ confidence limit $(<4.2 \mathrm{nmol} / \mathrm{l})$ used for the clinical reference range (14). Baseline data were compared by Mann-Whitney rank sum test and Kruskal-Wallis one-way ANOVA on ranks (Sigmaplot 11.0; Systat Software, Inc., San Jose, CA, USA). Circadian rhythm data were evaluated by two-factor ANOVA repeated on one factor (time) followed by pairwise multiple comparison using the Holm-Sidak method; data not normally distributed were evaluated after logarithmic transformation. Rates and proportions were analyzed by $\chi^{2}$ or Fisher's exact test. Linear regression/correlations were analyzed by Spearman's rank-order correlation and, where appropriate, with regression slopes and $y$-intercepts compared by $t$-test. $P<0.05$ was considered significant. Graphical data are presented as mean/s.E.m. whereas tabular data are presented as median $(25-75 \%$ confidence intervals).

\section{Results}

Subject characteristics and baseline study day data are shown in Table 1. The ESRD subjects and controls were well matched in terms of the primary matching criteria (demographic characteristics), although the ESRD subjects tended to be younger ( $t$-test, $P=0.076$; rank sum test, $P=0.046)$. The causes of ESRD included focal segmental glomerulosclerosis $(n=5)$, hypertension $(n=6)$, chronic interstitial nephritis $(n=1)$, chronic glomerulonephritis $(n=1)$, polycystic kidney disease $(n=1)$, post-streptococcal glomerulonephritis $(n=1)$, and unknown $(n=1)$

http://www.endocrineconnections.or

DOI: 10.1530/EC-12-0058
Table 1 Median (25-75\% confidence intervals) baseline data on enrollment and baseline plasma data at $0800 \mathrm{~h}$ on the day of cortisol sampling.

\begin{tabular}{|c|c|c|}
\hline Subject (n) & Control (8) & ESRD (16) \\
\hline Age (years) & $59(49-63)$ & $46(35-56)^{*, a}$ \\
\hline Height $(\mathrm{cm})^{\mathrm{b}}$ & $178(168-185)$ & $174(170-180)$ \\
\hline Weight $(\mathrm{kg})^{\mathrm{b}}$ & $84(75-88)$ & $79(68-88)$ \\
\hline Male/female & $6 / 2$ & $14 / 2$ \\
\hline Race $(W, A A)$ & $4 / 4$ & $8 / 8$ \\
\hline $\begin{array}{l}\text { Serum creatinine } \\
(\mu \mathrm{mol} / \mathrm{l})\end{array}$ & $80(71-88)$ & \\
\hline eGFR (ml/min) & $94(8-18)$ & \\
\hline URR (\%) & & $77(71-79)$ \\
\hline $\begin{array}{l}\text { Duration on } \\
\text { dialysis (months) }\end{array}$ & & $25(9-56)$ \\
\hline Serum albumin $(\mathrm{g} / \mathrm{l})$ & & $40(38-43)$ \\
\hline $\begin{array}{l}\text { Serum bicarbonate } \\
(\mathrm{mmol} / \mathrm{l})^{c}\end{array}$ & & $25.0(23.3-26.6)$ \\
\hline
\end{tabular}

ESRD, end-stage renal disease; W, White; AA, African-American; eGFR, estimated glomerular filtration rate; URR, urea reduction ratio. MannWhitney rank sum test: $* P<0.050$

${ }^{a}$ Age was not different by $t$-test $(P=0.076)$.

${ }^{\mathrm{b}} n=7$ for control group.

${ }^{c} n=15$ for ESRD group.

Figure 1 (left panels) shows the plasma and salivary cortisol and plasma ACTH results in control and ESRD subjects sampled every $2 \mathrm{~h}$ from $0800 \mathrm{~h}$ on day 1 to $0600 \mathrm{~h}$ on day 2 . Note that salivary cortisol was not sampled from 2400 to $0400 \mathrm{~h}$ when the subjects were sleeping. Also note that one ESRD subject was not included in the salivary cortisol analysis because of obvious contamination of the salivary cortisol samples as described previously (17). The control subjects had typical circadian plasma and salivary cortisol and plasma ACTH rhythm patterns. The patterns of plasma compared to salivary cortisol were similar. The ESRD subjects also had a discernable circadian rhythm; interestingly, there was a small increase in plasma and salivary cortisol at $1800 \mathrm{~h}$ such that they were not different from the $0800 \mathrm{~h}$ result on day 1 or the $0600 \mathrm{~h}$ result on day 2. On average, the ESRD subjects did not achieve the full circadian nadir as the plasma cortisol was higher than controls between 1800 and $2400 \mathrm{~h}$ and the salivary cortisol was higher between 1200 and $2200 \mathrm{~h}$. Plasma ACTH levels did not show a statistically detectable circadian rhythm in the ESRD subjects and were higher than controls from 1200 to $2400 \mathrm{~h}$.

Using the conservative $a$ priori criteria described in the Materials and methods section, the plasma and salivary

(c) 2012 The Authors. Published by BioScientifica Ltd. This is an Open Access article distributed under the terms of the Creative Commons Attribution License, which permits unrestricted use, distribution, and reproduction in any medium, provided the original author and source are credited. 

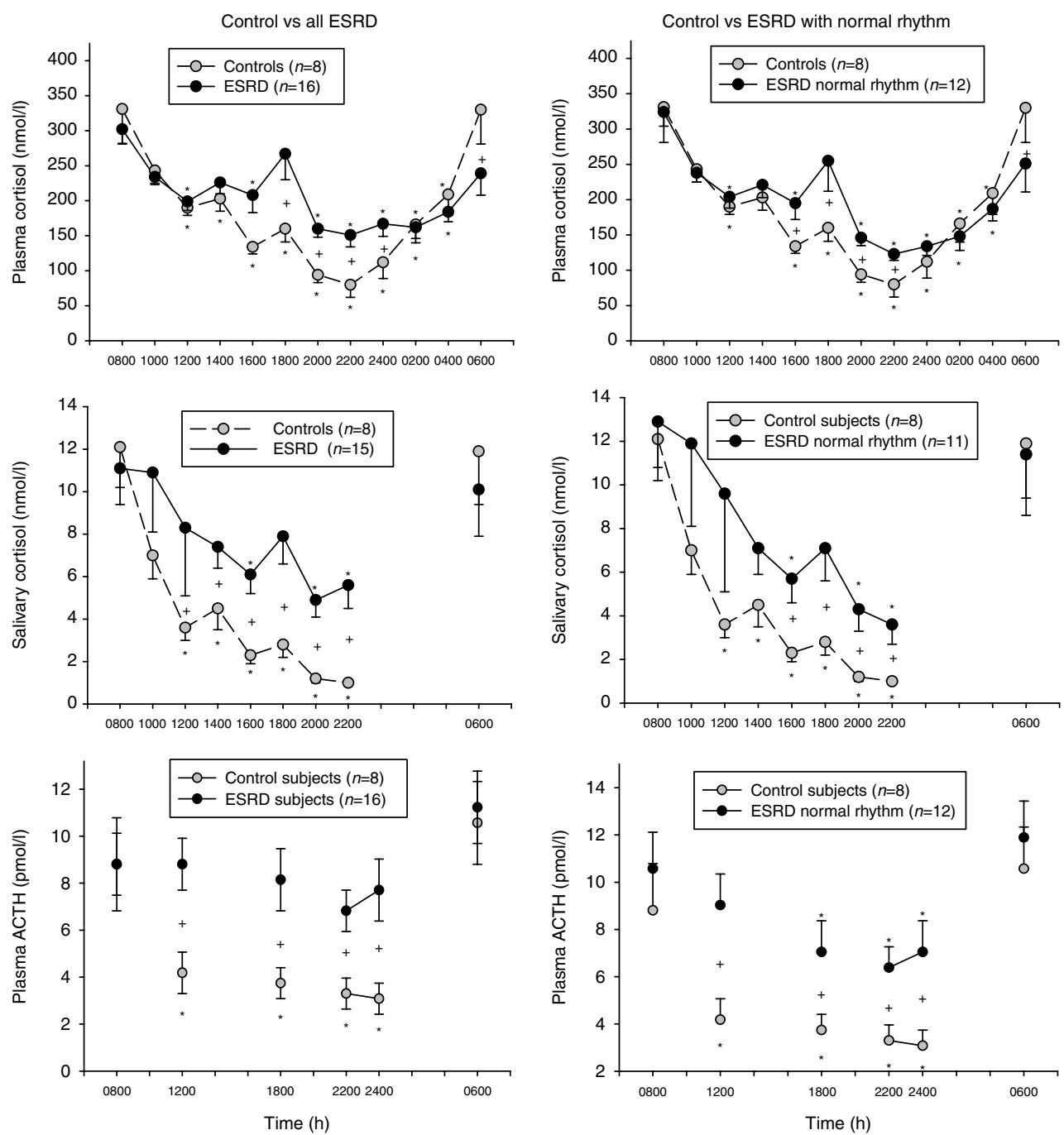

Figure 1

Plasma cortisol (top), salivary cortisol (middle), and plasma ACTH (bottom) in control subjects $(n=8)$ compared to all ESRD subjects (left; $n=16)$ or the subset of ESRD subjects who met the criteria for normal cortisol circadian rhythm (right; $n=12$ ). *Difference from $0800 \mathrm{~h}$ and ${ }^{+}$difference between

control and ESRD subjects at the same time point $(P<0.05)$. Note that salivary cortisol was not sampled between 2400 and $0400 \mathrm{~h}$ (sleep time) and plasma ACTH was not assessed at all time points.

cortisol levels were evaluated for the normality of the cortisol circadian rhythm. Twelve of the 16 ESRD subjects met the criteria for a normal circadian rhythm. Figure 1 (right panels) shows the plasma and salivary cortisol and plasma ACTH after removing from the analysis the data from the ESRD subjects not meeting the criteria of a normal cortisol rhythm. All the control subjects met the criteria for a normal rhythm. Even after removing four ESRD subjects that did not meet the criteria for a normal circadian rhythm from the analysis, the nighttime plasma and salivary cortisol levels were still significantly

http://www.endocrineconnections.org DOI: 10.1530/EC-12-0058

increased between 1600 and $2200 \mathrm{~h}$ compared with the control subjects.

Figure 2 shows the individual plasma and salivary cortisol and plasma ACTH data for the four ESRD subjects that did not meet the criteria for a normal circadian rhythm. Subject 1 seemed to have an inverted rhythm with a peak at $1800 \mathrm{~h}$ and a nadir at $0600 \mathrm{~h}$. This subject was not a night shift worker, had daytime dialysis like the other ESRD subjects, and had a normal sleep diary for the night before and the night of sampling. The other three subjects had no discernable circadian rhythms and also had normal sleep diary records.

C) 2012 The Authors. Published by BioScientifica Ltd. This is an Open Access article distributed under the terms of the Creative Commons Attribution License, which permits unrestricted use, distribution, and reproduction in any medium, provided the original author and source are credited. 

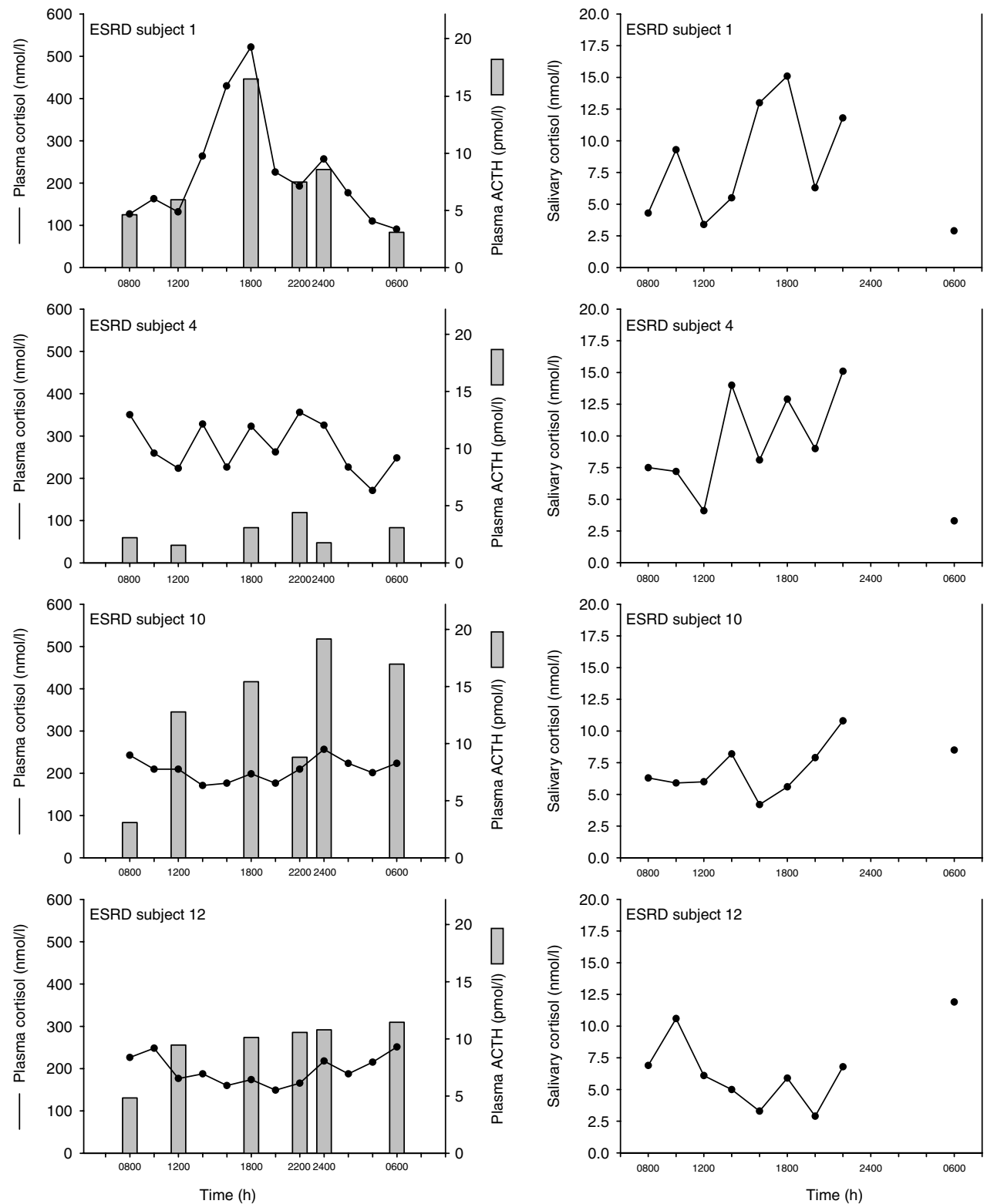

Figure 2

Plasma cortisol (lines) and ACTH (bars; left) and salivary cortisol (right) in the four subjects who did not meet the criteria for a normal cortisol circadian rhythm. Individual subjects are plotted from top to bottom.

Figure 3 shows the correlation of plasma and salivary cortisol individual results. First, note in the top panel that there were clearly contaminated salivary cortisol samples (increased salivary cortisol without increased plasma cortisol; see (17) for criteria for contamination of saliva samples). Even when this subject with contaminated saliva was eliminated from the analysis (bottom panel), there was no difference between the correlations of control vs ESRD subjects.

http://www.endocrineconnections.org DOI: 10.1530/EC-12-0058
We were then interested in determining whether any of the baseline data of the ESRD subjects partitioned by circadian cortisol rhythm could offer any explanation for the four ESRD subjects with abnormal circadian rhythms shown in Fig. 2. As shown in Table 2, there were no statistically significant differences between the two ESRD groups partitioned by circadian rhythm. The only measurement that approached statistical difference was the duration on dialysis. Although formal sleep studies

(C) 2012 The Authors. Published by BioScientifica Ltd. This is an Open Access article distributed under the terms of the Creative Commons Attribution License, which permits unrestricted use, distribution, and reproduction in any medium, provided the original author and source are credited. 

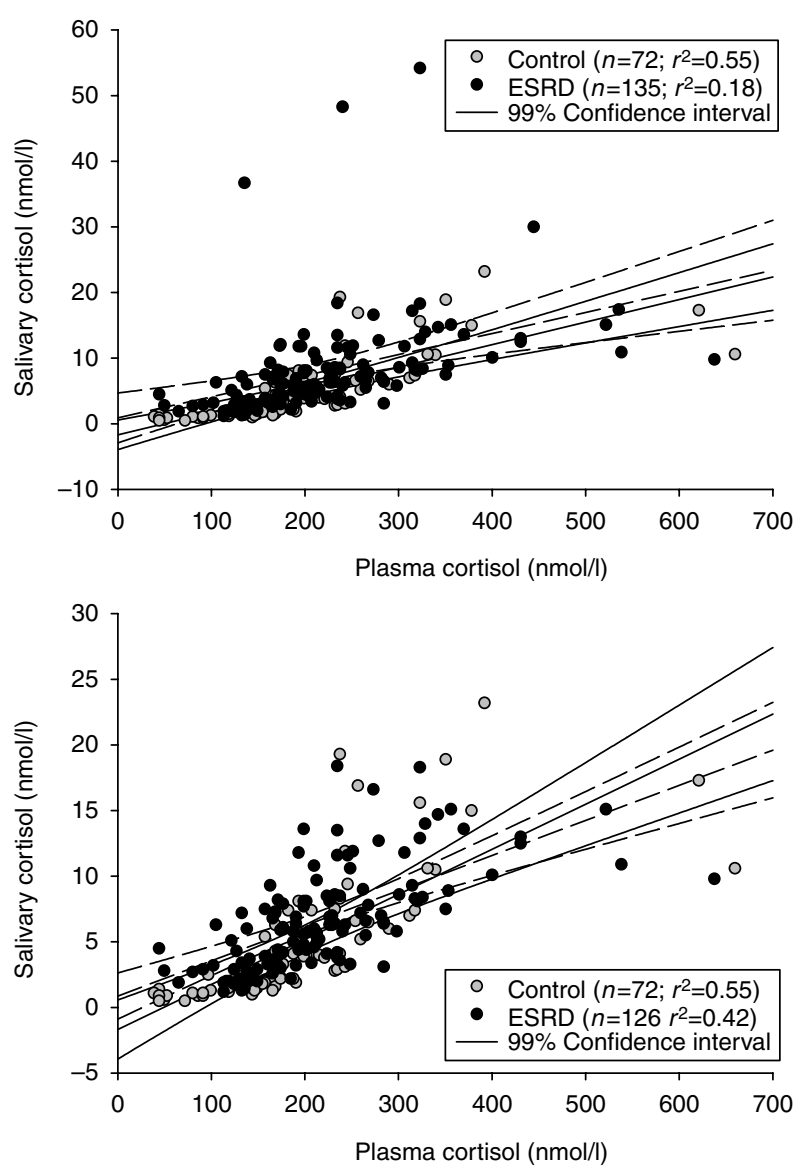

\section{Figure 3}

Correlation and linear regression ( $\pm 99 \%$ confidence intervals) of individual plasma and salivary cortisol levels in all control vs ESRD subjects (top) and in all control vs ESRD subjects without the obviously contaminated saliva samples (bottom) (17). The slopes and intercepts were not different between control (solid line) and ESRD (dashed lined) subjects in either graph. For the top panel, control subjects slope and $y$-intercept was $0.034 \pm$ 0.004 and $-1.7 \pm 0.9 \mathrm{nmol} / \mathrm{l}$ respectively and for ESRD subjects was $0.032 \pm$ 0.006 and $0.9 \pm 1.5 \mathrm{nmol} / \mathrm{l}$ respectively. For the bottom panel, the ESRD subjects slope and $y$-intercept was $0.027 \pm 0.003$ and $0.9 \pm 0.7 \mathrm{nmol} / \mathrm{l}$ respectively. The Spearman's rank-order correlation coefficients were 0.902 for the controls $(P<0.001)$ and 0.723 for the ESRD subjects $(P<0.001)$.

were not done simultaneously with cortisol sampling, analysis of the descriptive nurse's notes from the study did not identify any clear differences between the groups in Table 2. Serum calcium, phosphorus, and parathyroid hormone results were not different between the two ESRD groups (data not shown).

We used the small volume of remaining plasma (0800 h on day 1) from our subjects to measure CRP by a high-sensitivity assay to assess whether there could be association between a disrupted circadian HPA axis rhythm and an increased inflammatory state. Median (25-75\% confidence intervals) plasma CRP levels (nmol/l)

http://www.endocrineconnections.org

DOI: 10.1530/EC-12-0058 were 4.8 (3.9-59.0) in the control subjects, 53.5 (32.485.7) in the ESRD subjects with a normal cortisol circadian rhythm, and 147.6 (99.0-261.9) in the ESRD subjects with an abnormal circadian rhythm (one-way ANOVA on ranks; $P=0.019$ ).

\section{Discussion}

The initial purpose of this study was to evaluate the usefulness of salivary cortisol to evaluate the HPA axis in subjects with ESRD. We have now clearly demonstrated that salivary cortisol is a useful surrogate for plasma cortisol in ESRD patients in agreement with many previous studies of patients with Cushing's syndrome, hypoalbuminemia, corticosteroid-binding globulin mutations, and adrenal insufficiency $(6,7,18,19)$.

We also found that ESRD subjects had a significantly increased nadir in salivary and plasma cortisol concentrations. When the four ESRD subjects with dramatically abnormal circadian rhythms were excluded from the analysis, the remaining ESRD subjects still had statistically significant increases in circadian nadir plasma and salivary cortisol levels. At first, we thought this could be due to changes in plasma proteins and/or cortisol metabolism and clearance. Arguing against this was the normal plasma albumin in ESRD subjects (Table 1), the excellent correlation of plasma and salivary cortisol (a validated surrogate for plasma free cortisol (1)), and the clearly abnormal plasma ACTH rhythm (Fig. 1). It should also be noted that the control subjects had a typical and normal circadian pattern of cortisol concentration indicating that the sampling conditions were appropriate.

It has been suggested that patients with ESRD have a decreased sensitivity to glucocorticoid-negative feedback assessed by dexamethasone suppression (10). That study did not take into account potential differences in dexamethasone absorption and metabolism nor did it evaluate physiological glucocorticoid-negative feedback sensitivity at different times of day. It also needs to be considered that direct immunoassays overestimate cortisol concentrations with dexamethasone suppression in ESRD patients $(8,20,21)$. So it remains possible that ESRD patients have decreased glucocorticoid feedback sensitivity leading to an increase in plasma ACTH at the circadian nadir. One study demonstrated normal ACTH responses to ovine CRH in ESRD patients, whereas another from the same group suggested a blunted response indicating increased cortisol-negative feedback $(22,23)$. It is clear from our current study and previous studies that

C) 2012 The Authors. Published by BioScientifica Ltd. This is an Open Access article distributed under the terms of the Creative Commons Attribution License, which permits unrestricted use, distribution, and reproduction in any medium, provided the original author and source are credited. 
Table 2 Median (25-75\% confidence intervals) baseline data on enrollment and baseline plasma data at $0800 \mathrm{~h}$ on the day of cortisol sampling for ESRD subjects partitioned by normality of cortisol circadian rhythm.

\begin{tabular}{|c|c|c|}
\hline Subject ( $n$ ) & $\begin{array}{l}\text { Normal } \\
\text { rhythm (12) }\end{array}$ & $\begin{array}{l}\text { Abnormal } \\
\text { rhythm (4) }\end{array}$ \\
\hline Age (years) & $46(35-54)$ & $52(35-60)$ \\
\hline Height $(\mathrm{cm})$ & $174(169-180)$ & $176(171-181)$ \\
\hline Weight $(\mathrm{kg})^{\mathrm{a}}$ & $83(64-90)$ & $74(72-79)$ \\
\hline Male/female & $10 / 2$ & $4 / 0$ \\
\hline Race $(W, A A)$ & $5 / 7$ & $1 / 3$ \\
\hline Ethnicity $(\mathrm{H} / \mathrm{non}-\mathrm{H})$ & $1 / 11$ & $0 / 4$ \\
\hline URR (\%) & $79(71-80)$ & $76(72-77)$ \\
\hline $\begin{array}{l}\text { Duration on dialysis } \\
\text { (months) } \\
\text { Dialysis access }(n)\end{array}$ & $25(6-39)$ & $82(25-164) *$ \\
\hline AVG & 2 & 1 \\
\hline AVF & 9 & 2 \\
\hline PC & 1 & 1 \\
\hline Serum albumin $(\mathrm{g} / \mathrm{l})$ & $41(38-44)$ & $38(34-40)$ \\
\hline $\begin{array}{l}\text { Serum bicarbonate } \\
(\mathrm{mmol} / \mathrm{l})^{\mathrm{b}}\end{array}$ & $25.0(23.3-26.6)$ & $25.4(22.0-26.4)$ \\
\hline
\end{tabular}

ESRD, end-stage renal disease; W, White; AA, African-American; $H_{\text {, }}$ Hispanic; eGFR, estimated glomerular filtration rate; URR, urea reduction ratio; AVG, arteriovenous graft; AVF, arteriovenous fistula; $P C$, Permcath. Mann-Whitney rank sum test: ${ }^{*} P=0.162$ (all other comparisons, $P>0.200$ ). a $n=3$ for abnormal rhythm group.

${ }^{b} n=11$ for normal rhythm group.

the relationship between plasma ACTH and cortisol appears to be intact in ESRD patients $(24,25)$.

Early studies showed normal cortisol rhythms in ESRD patients $(10,26)$, whereas more recent studies not specifically designed for this purpose have suggested a disrupted circadian rhythm $(27,28)$. The reason for this change over time is not clear, but it may be related to changes in characteristics of ESRD subjects. We do not think it is related to historical changes in the treatment of ESRD as there has been an improvement in the efficiency of hemodialysis therapy since the 1970s. Thus, if at all, one might expect metabolic abnormalities would be fewer and less severe in more recent years. The ESRD group tended to be younger than the control group. This age difference cannot account for the results we observed as older subjects, if anything, have increased late-night salivary cortisol and diminished sensitivity to glucocorticoid-negative feedback compared with younger subjects $(29,30,31)$.

It was intriguing that small subset of ESRD subjects showed a dramatically abnormal ACTH and cortisol

http://www.endocrineconnections.org

DOI: 10.1530/EC-12-0058 circadian rhythm. We could not identify any clinical correlate that could account for this (Table 2). The only variable that was even suggestive of a difference between ESRD subjects with normal and abnormal rhythms was the duration on dialysis, although there was clearly significant overlap of this variable between the two ESRD subgroups.

Subjects with chronic kidney disease have elevated markers of inflammation that are associated with a range of abnormalities including resistance to erythropoiesisstimulating agents and increased morbidity (13). Although we did not initially intend to evaluate the possibility of a heightened inflammatory state, we were able to measure plasma CRP in the very small amount of plasma remaining at the end of the study. Our CRP data with admittedly small numbers of subjects are suggestive of an association of an increase in plasma CRP with a disrupted cortisol circadian rhythm. There is a welldocumented increase in CRP in ESRD patients $(32,33)$ as well as an association of the immune and HPA axes $(34,35$, 36). Although much work remains to be done on this topic and our CRP studies are post hoc and preliminary, it seems possible that ESRD patients with an increased inflammatory state may have a higher propensity for a disrupted circadian rhythm and/or decreased sensitivity to cortisolnegative feedback. Further, if these results are validated, further studies should investigate whether disrupted cortisol rhythm has clinical sequelae such as increased morbidity or mortality in ESRD subjects.

In conclusion, the measurement of salivary cortisol is a useful surrogate for plasma cortisol in patients with ESRD. This should facilitate the evaluation of these patients for the potential diagnosis of Cushing's syndrome. This is important as the stigmata of Cushing's syndrome are common in ESRD patients (13). In fact, it has been suggested that some of the sequelae of ESRD may be due to increased stress hormone concentrations $(8,9)$. It is also important to reiterate that salivary cortisol is a validated surrogate for plasma free cortisol - the biologically active component of the HPA axis. As we have described previously for elderly subjects, the exposure of the tissues and organs to twice or three times higher free cortisol concentration night after night for months to years is likely to result in significant negative consequences (29).

Taking into account the increased late-night cortisol levels, the increase in plasma ACTH, and previous studies showing diminished sensitivity to glucocorticoid feedback, we suggest that ESRD may represent a state of ACTH-dependent hypercortisolism. Therefore, from a diagnostic point of view, we propose that an increased

(c) 2012 The Authors. Published by BioScientifica Ltd. This is an Open Access article distributed under the terms of the Creative Commons Attribution License, which permits unrestricted use, distribution, and reproduction in any medium, provided the original author and source are credited. 
late-night salivary cortisol in patients with ESRD should be interpreted with great caution. Whereas this measurement has a 95\% sensitivity and specificity for Cushing's syndrome in patients without chronic kidney disease (6), we now suggest an increased likelihood of false-positive results in patients with ESRD, particularly considering the extremely low probability that any of the ESRD patients had endogenous Cushing's syndrome. This is similar to previous studies in patients with diabetes mellitus (37). It is important to reiterate that this study was powered to compare the circadian rhythms of salivary and plasma cortisol and that the findings of markedly abnormal salivary and plasma cortisol levels were somewhat of a surprise. An important next step would be to evaluate a large number of patients with various degrees of renal failure to establish disease-specific reference ranges for late-night salivary cortisol.

Therefore, if late-night salivary cortisol is normal, Cushing's syndrome can be ruled out in ESRD patients. However, we measured late-night salivary cortisol levels as high as $15 \mathrm{nmol} / \mathrm{l}$ in ESRD patients (clinical reference range $<4.2 \mathrm{nmol} / \mathrm{l}$ ). Therefore, because of both subtly and strikingly abnormal late-night plasma and salivary cortisol levels, the evaluation of ESRD patients for true Cushing's syndrome continues to be quite challenging.

\section{Declaration of interest}

$\mathrm{H}$ Raff has nothing to disclose. $\mathrm{H}$ Trivedi consults for Abbott Laboratories (Advisory Board).

\section{Funding}

Lemann Endowment Grant, Genzyme Research Grant, UL1RR031973 from the Clinical and Translational Science Award (CTSA) program of the National Center for Research Resources and the National Center for Advancing Translational Sciences, and Aurora Health Care PatientCentered Research.

\section{Acknowledgements}

The authors thank the staff of the Adult Translational Research Unit, Mary Hannan, ACNP for data collection, Char Klis for administrative support, Peter Homar and Barbara Jankowski for technical assistance, and James Findling for reviewing the manuscript.

\section{References}

1 Raff H. Utility of salivary cortisol measurements in Cushing's syndrome and adrenal insufficiency. Journal of Clinical Endocrinology and Metabolism 200994 3647-3655. (doi:10.1210/jc.2009-1166)

2 Raff H. Cushing's syndrome: diagnosis and surveillance using salivary cortisol. Pituitary 201215 64-70. (doi:10.1007/s11102-011-0333-0)

http://www.endocrineconnections.org

DOI: 10.1530/EC-12-0058
3 Carroll T, Raff H \& Findling JW. Late-night salivary cortisol measurement in the diagnosis of Cushing's syndrome. Nature Clinical Practice. Endocrinology \& Metabolism 20084 344-350. (doi:10.1038/ ncpendmet0837)

4 Raff $\mathrm{H}$. The role of salivary cortisol determinations in the diagnosis of Cushing's syndrome. Current Opinion in Endocrinology \& Diabetes 2004 11 271-275. (doi:10.1097/01.med.0000132655.69704.8c)

5 Raff $\mathrm{H} \&$ Findling JW. A physiologic approach to the diagnosis of Cushing syndrome. Annals of Internal Medicine 2003138 980-991. (doi:10.7326/0003-4819-138-12-200306170-00010)

6 Carroll T, Raff H \& Findling JW. Late-night salivary cortisol for the diagnosis of Cushing's syndrome: a meta-analysis. Endocrine Practice 200915 335-342. (doi:10.4158/EP09023OR)

7 Raff H, Raff JL \& Findling JW. Late-night salivary cortisol as a screening test for Cushing's syndrome. Journal of Clinical Endocrinology and Metabolism 199883 2681-2686. (doi:10.1210/jc.83.8.2681)

8 N'Gankam BM, Uehlinger FJ, Dick B, Frey BM \& Frey FJ. Increased cortisol metabolites and reduced activity of 11- $\beta$-hydroxysteroid dehydrogenase in patients on hemodialysis. Kidney International 2002 61 1859-1866. (doi:10.1046/j.1523-1755.2002.00308.x)

9 Letizia C, Mazzaferro S, De Ciocchis A, Cerci S, Morabito S, Cinotti GA \& Scavo D. Effects of haemodialysis session on plasma $\beta$-endorphin, ACTH and cortisol in patients with end-stage renal disease. Scandinavian Journal of Urology and Nephrology 199630 399-402. (doi:10.3109/ 00365599609181317)

10 Wallace EZ, Rosman P, Toshav N, Sacerdote A \& Balthazar A. Pituitaryadrenocortical function in chronic renal failure: studies of episodic secretion of cortisol and dexamethasone suppressibility. Journal of Clinical Endocrinology and Metabolism 198050 46-51. (doi:10.1210/ jcem-50-1-46)

11 U.S. Renal Data System. USRDS Annual Data Report: Atlas of Chronic Kidney Disease and End-Stage Renal Disease in the United States, National Institutes of Health, National Institute of Diabetes and Digestive and Kidney Diseases, Bethesda, MD, 2010 (http://www. usrds.org/).

12 CDC. Prevalence of chronic kidney disease and associated risk factors, United States, 1999-2004. MMWR Weekly 56 (08) 151-165 2007 (http://www.cdc.gov/mmwr/preview/mmwrhtml/mm5608a2.htm).

13 Bargman JM \& Skorecki K. Chronic kidney disease. In Harrison's Principles of Internal Medicine, edn 18, ch 280. Eds DL Longo, AS Fauci, DL Kasper, SL Hauser, LJ Jameson \& J Loscalzo. New York: McGraw-Hill, 2012. Retrieved May 31, 2012 from http://www.accessmedicine.com/ content.aspx?aID=9130075

14 Raff H, Homar PJ \& Skoner DP. A new enzyme immunoassay for salivary cortisol. Clinical Chemistry 200349 203-204. (doi:10.1373/49.1.203)

15 Wilkinson CW \& Raff H. Comparative evaluation of a new immunoradiometric assay for corticotropin. Clinical Chemistry and Laboratory Medicine 200644 669-671. (doi:10.1515/CCLM.2006.113)

16 Papanicolaou DA, Yanovski JA, Cutler GB, Chrousos GP \& Nieman LK. A single midnight cortisol measurement distinguishes Cushing's syndrome from pseudo-Cushing states. Journal of Clinical Endocrinology and Metabolism 199883 1163-1167. (doi:10.1210/jc.83.4.1163)

17 Raff H \& Singh RJ. Measurement of late night salivary cortisol and cortisone by liquid chromatography-tandem mass spectrometry to assess pre-analytical sample contamination with topical hydrocortisone. Clinical Chemistry 201258 947-948. (doi:10.1373/clinchem.2012. 182717

18 Perogamvros I, Keevil BG, Ray DW \& Trainer PJ. Salivary cortisone is a potential biomarker for serum free cortisol. Journal of Clinical Endocrinology and Metabolism 201095 4951-4958. (doi:10.1210/jc. 2010-1215)

19 Raff H, Brock S \& Findling JW. Cosyntropin-stimulated salivary cortisol in hospitalized patients with hypoproteinemia. Endocrine $2008 \mathbf{3 4}$ 68-74. (doi:10.1007/s12020-008-9101-y)

20 Van Herle AJ, Birnbaum JA, Slomowitz LA, Mayes D, Chandler DW, Rosenblit PD \& Nissenson A. Paper chromatography prior to cortisol

(C) 2012 The Authors. Published by BioScientifica Ltd. This is an Open Access articl distributed under the terms of the Creative Commons Attribution License, which permits unrestricted use, distribution, and reproduction in any medium, provided the original author and source are credited. 
RIA allows for accurate use of the dexamethasone suppression test in chronic renal failure. Nephron 199880 79-84. (doi:10.1159/000045132)

21 Vigna L, Buccianti G, Orsatti A, Cresseri D, Bianchi ML, Cremagnani L \& Cantalamessa L. The impact of long-term hemodialysis on pituitaryadrenocortical function. Renal Failure 199517 629-637. (doi:10.3109/ 08860229509037629)

22 Siamopoulos KC, Dardamanis M, Kyriaki D, Pappas M, Sferopoulos G \& Alevisou V. Pituitary adrenal responsiveness to corticotropin-releasing hormone in chronic uremic patients. Peritoneal Dialysis International 199010 153-156.

23 Siamopoulos KC, Eleftheriades EG, Pappas M, Sferopoulos G \& Tsolas O. Ovine corticotropin-releasing hormone stimulation test in patients with chronic renal failure: pharmacokinetic properties, and plasma adrenocorticotropic hormone and serum cortisol responses. Hormone Research 198830 17-21. (doi:10.1159/000181019)

24 Arreger AL, Cardoso EM, Tumilasci O \& Contreras LN. Diagnostic value of salivary cortisol in end stage renal disease. Steroids 2008 73 77-82. (doi:10.1016/j.steroids.2007.09.001)

25 Clodi M, Riedl M, Schmaldienst S, Vychytil A, Kotzmann H, Kaider A, Bieglmayer C, Mayer G, Waldhausl W \& Luger A. Adrenal function in patients with chronic renal failure. American Journal of Kidney Diseases 199832 52-55. (doi:10.1053/ajkd.1998.v32.pm9669424)

26 Cooke CR, Whelton PK, Moore MA, Caputo RA, Bledsoe T \& Walker WG. Dissociation of the diurnal variation of aldosterone and cortisol in anephric subjects. Kidney International 197915 669-675. (doi:10.1038/ki.1979.87)

27 Morineau G, Boudi A, Barka A, Gourmelen M, Degeilh F, Hardy N, Al-Halnak A, Soliman H, Gosling JP, Julien R et al. Radioimmunoassay of cortisone in serum, urine, and saliva to assess the status of the cortisol-cortisone shuttle. Clinical Chemistry 199743 1397-1407.

28 Solomon R \& Dubey A. Diltiazem enhances potassium disposal in subjects with end-stage renal disease. American Journal of Kidney Diseases $199219420-426$

29 Raff H, Raff JL, Duthie EH, Wilson CR, Sasse EA, Rudman I \& Mattson D. Elevated salivary cortisol in the evening in healthy elderly men and women: correlation with bone mineral density. Journals of Gerontology.
Series A, Biological Sciences and Medical Sciences 1999 54A M479-M483. (doi:10.1093/gerona/54.9.M479)

30 Wilkinson CW, Peskind ER \& Raskind MA. Decreased hypothalamicpituitary-adrenal axis sensitivity to cortisol feedback inhibition in human aging. Neuroendocrinology 199765 79-90. (doi:10.1159/ 000127167)

31 Wilkinson CW, Petrie EC, Murray SR, Colasurdo EA, Raskind MA \& Peskind ER. Human glucocorticoid feedback inhibition is reduced in older individuals: evening study. Journal of Clinical Endocrinology and Metabolism 200186 545-550. (doi:10.1210/jc.86.2.545)

32 Grootendorst DC, de Jager DJ, Brandenburg VM, Boeschoten EW, Krediet RT, Dekker FW \& the NECOSAD Study Group . Excellent agreement between $\mathrm{C}$-reactive protein measurement methods in end-stage renal disease patients - no additional power for mortality prediction with high-sensitivity CRP. Nephrology, Dialysis, Transplantation 200722 3277-3284. (doi:10.1093/ndt/gfm381)

33 Lacson E \& Levin NW. C-reactive protein and end-stage renal disease. Seminars in Dialysis 200417 438-448. (doi:10.1111/j.0894-0959.2004. 17604.x)

34 Spinedi E, Hadid R, Daneva T \& Gaillard RC. Cytokines stimulate the $\mathrm{CRH}$ but not the vasopressin neuronal system: evidence for a median eminence site of interleukin-6 action. Neuroendocrinology $1992 \mathbf{5 6}$ 46-53. (doi:10.1159/000126207)

35 Mastorakos G, Weber JS, Magiakou MA, Gunn H \& Chrousos GP. Hypothalamic-pituitary-adrenal axis activation and stimulation of systemic vasopressin secretion by recombinant interleukin-6 in humans: potential implications for the syndrome of inappropriate vasopressin secretion. Journal of Clinical Endocrinology and Metabolism 199479 934-939. (doi:10.1210/jc.79.4.934)

36 Jacobson L. Hypothalamic-pituitary-adrenocortical axis regulation. Endocrinology and Metabolism Clinics of North America 200534 271-292. (doi:10.1016/j.ecl.2005.01.003)

37 Liu H, Bravata DM, Cabaccan J, Raff H \& Ryzen E. Elevated late-night salivary cortisol levels in elderly male type 2 diabetic veterans. Clinical Endocrinology 200563 642-649. (doi:10.1111/j.1365-2265. 2005.02395.x)

Received in final form 10 October 2012

Accepted 17 October 2012 